\title{
ESTRUTURA DE MERCADO E BEM ESTAR NO SEGMENTO DE CARROS DE 1000 CILINDRADAS NO BRASIL DE 2005
}

\section{A 2014}

Pedro Santos de Almeida (RIOgaleão e UFF);

Graciela Aparecida Profeta (DEE/CADE e UFF);

Tanise Brandão Bussman (DEE/CADE e UNIPAMPA)

resumo:

O objetivo desta pesquisa foi analisar a estrutura de mercado e mensurar o bem-estar social no segmento de carros de 1000 cilindradas no Brasil no período de 2005 a 2014. A sustentação teórica foi com a Nova Organização Industrial e Empírica e também de discussões sobre o a mensuração do peso morto, geralmente presente em mercados concentrados. Na análise empírica, utilizou-se de abordagem econométrica com modelos de dados em painel para encontrar os coeficientes da relação entre a demanda por carros 1000 cilindradas no Brasil e seus determinantes e a partir desses calculou-se o DWL. Os resultados sugerem que o mercado de carros 1000 cilindradas no Brasil, de 2005 a 2014, é concentrado; a demanda é inelástica ao preço; e, houve um significativo valor para o peso morto neste segmento, indicando a perda de bem-estar no setor.

\section{palavras-chave:}

Carros 1000 cilindradas no Brasil; Concentração de mercado; Características da demanda; DWL.

\section{Código JEL:}

D60, L16

\section{Área Temática:}

Competição, preços e estruturas de mercado 


\section{INTRODUÇÃO}

A indústria automobilística tem um papel relevante na dinâmica econômica, por envolver várias cadeias produtivas, como autopeças, serviços, etc. De acordo com informações da Associação Nacional de Fabricantes de Veículos Automotores- ANFAVEA (2020), em 2019 o mercado interno apresentou vendas da ordem de 2,78 milhões (8,4\% a mais que em 2018), porém 1 milhão abaixo do pico de vendas verificado em 2012. Embora esses, números indiquem que o Brasil, ocupa a sexta posição no ranking global de vendas de veículos, há de lembrar que o país já foi o quarto maior mercado mundial.

Observa-se que no final da década de 1980 e início da década de 1990, a indústria automobilística experimentou um crescimento dos chamados mercados emergentes que fez com que essas indústrias migrassem para países onde havia algum incentivo para o setor. O Brasil foi um dos países que se beneficiou desta modificação (SANT'ANNA, 2010).

De acordo com De Negri (1998) e Portugal (1994), um fator que deve ser destacado no caso Brasileiro foi a abertura comercial ocorrida no início dos anos 1990, e que pode ser analisada a partir de duas fases. A primeira é caracterizada pela extinção de barreiras tarifárias que favoreciam a indústria nacional até 1990. Nesse momento, foram extintos controles administrativos sobre as importações e começou uma redução do imposto de importação de diversos produtos, principalmente os relacionados ao setor automobilístico. Até a abertura comercial, as montadoras General Motors, Fiat, Volkswagen e Ford operavam no mercado de automóveis brasileiro quase que de forma absoluta (TORRES; CARIO, 2012). Além disso, nessa década o Brasil passou por modificações que incluíram mudanças na composição de sua indústria automobilística. Complementarmente, com o regime automotivo de 1995, iniciou-se então um processo de reestruturação do setor industrial, em que houve um aumento da competitividade em geral.

Com o efeito da abertura comercial e com a reestruturação que o setor passou, devido ao regime automotivo brasileiro, a entrada de novas montadoras estrangeiras e o encerramento da produção puramente advinda das montadoras nacionais, e a indústria automobilística brasileira assumiu papel crucial para a economia brasileira. Sobre o crescimento do setor nota-se que, em 2004, foram registrados 88.783 funcionários e, em 2009, esse número foi de 109.043 funcionários (ANFAVEA, 2010). Além disso, a participação industrial de 2004 a 2012 reduziu-se de forma drástica: Em 2004, a fatia de contribuição do setor automotivo para o PIB caiu de 19,2\%, em 2004, para $13,3 \%$, em 2012. A taxa foi a menor desde 1955, quando a participação chegou a $13,1 \%$ (FEDERAÇÃO DAS INDÚSTRIAS DO ESTADO DE SÃO PAULO - FIESP, 2013). Entretanto, nota-se que tal setor é bastante relevante ainda em termos econômicos, com uma contribuição superior à 10\% do PIB (ANFAVEA, 2016).

Considerando os anos de 2005, 2010, 2014 e 2015, observou-se que a participação do segmento de carros de 1000 cilindradas em relação ao número de licenciamentos total era de 52,4\%, $47,2 \%, 36,10 \%$ e $33,8 \%$, respectivamente. Mesmo com a queda da participação desse seguimento no total de veículos licenciados no Brasil, ainda sim, trata-se de um segmento de mercado importante para a indústria de automóvel no Brasil (ANFAVEA, 2016). Ademais, a indústria automobilística, apesar da abertura comercial de 1990, não apresenta um número grande de players no Brasil que ofertam carros de 1000 cilindradas, visto que apenas a General Motors, Ford, Renault, Fiat e Volkswagen atuam nesse segmento.

A partir do exposto acima, cabem os seguintes questionamentos: Qual o comportamento do consumidor no segmento de automóveis de 1000 cilindradas no Brasil no período de 2005 a 2014? E ainda, existe perda de bem-estar social (DWL) nesse mercado? Neste sentido, o objetivo desta pesquisa consistiu em analisar as características do mercado, a demanda e os efeitos no bem-estar social no segmento de carros de 1000 cilindradas no Brasil no período de 2005 a 2014.

Destaca-se que o período de análise da pesquisa se limitou ao intervalo de tempo entre 2005 e 2014, período marcado pelos governos dos ex-presidentes Lula e Dilma. De 2002 a 2006 a economia 
brasileira aproveitou-se do significativo volume de comodities exportadas, o que gerava crescimento econômico e aumento de renda da população. Já no segundo governo Lula, de 2006 a 2010, o país teve taxa de crescimento da economia superior a outras economias do mundo, que sinalizava aos investidores um cenário de estabilidade e crescimento, o que mais uma vez contribuiria para a indústria nacional e para o aumento da renda dos brasileiros. Já no governo Dilma, de 2011 a 2014, a economia brasileira passou por períodos de alta e baixa, principalmente no fim do mandato, com o impeachment da presidente Dilma. Além das questões econômicas e políticas, considerou-se também na escolha do período, que se limitou à 2014, a dificuldade de obtenção de dados, visto que até 2014 a ANFAVEA permitia acesso livre às informações, após esse ano, o acesso aos dados foi limitado a assinantes.

Além desta seção introdutória, o presente artigo conta com um breve referencial teórico, seguido de uma seção metodológica, que descrevem a base de dados e os métodos utilizados. $\mathrm{Na}$ sequência, há uma seção de resultados e são expostas as principais conclusões da análise.

\section{REFERENCIAL TEÓRICO}

Para alcançar aos objetivos propostos neste estudo, foi necessário entender algumas discussões teóricas importantes, como as caraterísticas da curva de demanda, necessária para o cálculo da perda de bem-estar social; a questão do mercado relevante; e, como se observa a perda de bemestar social (DWL). Logo, nesta seção, serão discutidas tais questões.

\subsection{Curva de demanda}

Observa-se que quando o preço de um determinado bem aumenta, ceteris paribus, leva a uma menor quantidade demandada deste bem; e, por outro lado, um preço mais baixo leva a uma maior quantidade demandada. Essa relação inversamente proporcional entre preço e quantidade demandada é conhecida como Lei da Demanda. Sendo assim, no gráfico preço-quantidade, a inclinação da curva é negativa, uma vez que a demanda reduzirá quando o preço aumentar, e vice-versa. As oscilações na curva de demanda que decorrem da variação de preço são conhecidas como elasticidade-preço da demanda, e podem ser descritas conforme Equação (1).

$$
E_{P}=\frac{\frac{\Delta Q}{Q}}{\frac{\Delta P}{P}} \rightarrow E_{P}=\frac{\Delta Q}{\Delta P} * \frac{P}{Q}
$$

em que $\Delta \mathrm{Q}$ e $\Delta \mathrm{P}$, representam, respectivamente, a variação infinitesimal na Quantidade (Q) e no Preço (P). Caso a elasticidade seja maior do que 1, diz-se que a mesma é elástica, caso seja menor do que 1 , ela é inelástica, e caso ela seja exatamente 1, é considerada unitária. Destaca-se que a sensibilidade da demanda é fundamental para a percepção de qualquer tipo de mercado sobre o comportamento do consumidor, uma vez que permite inferir o que ocorrerá no mercado consumidor caso os preços sejam modificados.

Dependendo do comportamento da demanda, é possível que a empresa opte por um aumento de preços para ser capaz de aumentar seu lucro, principalmente quando a demanda é inelástica. Quando isso ocorre, os consumidores, que passam a pagar um valor superior pelo produto apresentam uma perda de bem estar. Muitas vezes, o aumento de bem estar auferido pela firma não é capaz de compensar a redução que ocorre com os consumidores, indicando, neste caso, uma perda de bem estar social, ou seja, a sociedade como um todo fica em uma situação pior com o aumento de preços pela empresa.

No caso do mercado automobilístico, levando em conta a concentração de mercado e as características dos produtos ofertados (havendo um esforço para a diferenciação dos mesmos), há uma tendência de que a demanda seja inelástica 


\subsection{Mercado relevante e Poder de Mercado}

Seguindo o exposto por Possas (1996), a definição do mercado é o menor mercado, de acordo com o tamanho do espaço econômico, onde as empresas possam exercer suas atividades. Logo, definilo constitui tarefa indispensável para que seja possível reprimir atividades tidas como abusivas decorrentes do exercício do poder de mercado em determinada região. Para o Conselho Administrativo de Defesa Econômica - CADE (2016)

A delimitação do Mercado Relevante é o processo de identificação do conjunto de agentes econômicos (consumidores e produtores) que efetivamente reagem e limitam as decisões referentes a estratégias de preços, quantidades, qualidade (entre outras) da empresa resultante da operação (CADE, 2016, p. 13).

A Resolução 20/99 do CADE, por sua vez, define a delimitação de mercado relevante como "o espaço - em suas dimensões produto e geográfica - no qual é razoável supor a possibilidade de abuso de posição predominante" (CADE, 1999).

São três os pressupostos que devem ser entendidos, segundo Possas (1996), para que o mercado possa ser corretamente definido, sejam eles: i) a relação produção e dimensão geográfica, que são indispensáveis, uma vez que o produto pode significar um grupo de produtos que não sejam necessariamente idênticos, mas que sejam substitutos com grau de substitutibilidade sem determinação; ii) definir o mercado nada mais é que um exercício preliminar de observação de uma determinada atividade econômica e sua atuação numa região.

Assim, quando há o encontro da demanda daquele local com o produto em questão, há a definição de um mercado. Segundo Possas (1996), determinar o mercado relevante consiste em observar as condições técnico-econômicas estruturais nas quais o exercício do poder de mercado em termos de preços (e quantidades) seja logicamente possível.

Tal definição é importante pois, no caso em questão, ela delimita o espaço em que as empresas exercem influência, indicando em qual raio é possível exercer o poder de mercado. O poder de mercado é a capacidade de, ao aumentar o preço de forma unilateral, apresentar aumentos de lucros individualmente. Quanto maior for esta capacidade, maior é o poder de mercado desta empresa.

Na economia neoclássica, o principal objetivo da firma é a maximização de lucros e isso ocorre, geralmente, quando é possível definir preços mais altos e operar com custos menores, ou apresentar economias de escalas. Assim, quando uma firma obtém poder de mercado, e o exerce, é provável que a mesma cause uma perda de bem-estar social (DWL) considerável.

\subsection{Modelos Clássicos e Contemporâneos da Economia Industrial}

A partir da década de 1990, foram desenvolvidos modelos que ficaram conhecidos como estes com base na Nova Organização Industrial Empírica (New Empirical Industrial Organization - NEIO), que vinha como uma crítica a abordagem Estrutura-Conduta-Desempenho (ECD), principalmente quanto aos seus pressupostos.

De acordo com modelos baseados no paradigma ECD, o poder de mercado será maior quanto mais elevada for a concentração e as barreiras para entrada no mercado. Portanto, medidas de concentração e de escala mínima de eficiência, como o CR4, podem ser utilizados para quantificar o poder de mercado (CHURCH; WARE, 2000). Todavia, essas medidas não representam o nível de poder de mercado correto de uma indústria, uma vez que não levam em apreço a elasticidade-preço da demanda, que é um determinante da reação dos consumidores mediante as alterações dos preços. $\mathrm{E}$, é exatamente por isso que esses modelos baseados nos paradigmas ECD são criticados com 
frequência por pesquisas em que, dentre os pontos de estudo, encontra-se o poder de mercado.

O paradigma ECD tem como ideia inicial que o poder de mercado é calculado a partir da comparação entre o preço e custo marginal das firmas que participam de determinado mercado. Uma vez que o poder de mercado é palpável, o custo marginal poderia ser diretamente obtido via dados contábeis. Bresnahan (1989), afirma que tais custos podem não ser acessíveis, indicando uma possível falha neste paradigma.

A abordagem da NEIO utiliza algumas hipóteses do paradigma ECD, mas sem a formulação empírica fundamentada em custos marginais, enfatizando, por exemplo, modelos de Teoria dos Jogos. No caso da abordagem proposta pela NEIO, o grau de poder de mercado é identificado e estimado por meio da análise da conduta das empresas; ou seja, pelo comportamento tácito das firmas, observado nos dados de preço e na quantidade de equilíbrio de mercado (CHATURVEDI; BANDYOPADDHYAY, 2001).

Logo os modelos da NEIO buscam aferir o grau de poder de mercado por meio da assimilação de um parâmetro de conduta, com custos marginais não observáveis (ZEIDAN, 2005). Além disso, Baker e Bresnahan (1992) citaram três formas de detectar o poder de mercado: a) resposta dos preços a variações na elasticidade-preço da demanda; b) resposta dos preços a variações no custo marginal; e, c) detecção de múltiplos regimes de preços.

\subsection{Níveis de bem-estar}

Os mercados em que a competição é imperfeita têm como característica, quase sempre, apresentar diferenças entre preços e custos marginais. Essa diferença gera excedentes que são apropriados por uma indústria ou firma. Esses excedentes geralmente não são suficientes para compensar as perdas atribuídas aos consumidores devido às elevações dos preços de mercado. Por conseguinte, os resultados, geralmente, mostram uma perda líquida (DWL) que nada mais é do que o custo para a sociedade como um todo devido à ineficiência do mercado. Logo, ao somar tanto os ganhos das empresas com aquelas perdas pelos indivíduos, em geral, o resultado é negativo, indicando uma perda para a sociedade.

De acordo com Martin (1993), a transferência de renda do consumidor para o produtor, ocasionada pela prática do poder de mercado, não pode ser considerada perda de bem-estar social quando é compensada pelo lucro do monopólio que é transferido aos proprietários das firmas. Pois em tal situação não haveria uma perda do ponto de vista da sociedade (MARTIN, 1993).

O primeiro estudo que procurou determinar a perda de bem-estar social utilizou como hipóteses um monopólio em que a firma apresentava custo marginal constante e uma curva de demanda com elasticidade unitária, foi realizado por Harberger (1954). Este autor focou seu estudo no setor manufatureiro nos EUA, assumindo também que o objetivo da firma era o de definir o preço acima do custo marginal com o intuito de reduzir o excedente do consumidor e aumentar o lucro relativo ao de um ambiente competitivo. A diferença entre a perda do excedente do consumidor e o ganho do produtor representa a perda de bem-estar líquida, ao invés da redistribuição do consumidor ao produtor quando o mercado deixa de ser competitivo passando a monopolista. Assim, a primeira formulação do cálculo da perda de bem-estar (DWL) em estrutura de monopólio, sugerida por Harberger (1954), foi então definida conforme a Equação (2).

$D W L=\left(\frac{1}{2}\right)(\Delta p)(\Delta q)$

em que $\Delta \mathrm{p}=\mathrm{p}_{\mathrm{m}}-\mathrm{p}_{\mathrm{c}}$ e $\Delta \mathrm{q}=\mathrm{q}_{\mathrm{m}}-\mathrm{q}_{\mathrm{c}}$ representam, respectivamente, desvios do preço e da quantidade produzida do equilíbrio competitivo que resulta de um exercício de poder de mercado. Harberger (1954) tinha consciência das limitações das hipóteses por ele criadas em relação à estrutura de mercado e ao comportamento da demanda. Entretanto, o objetivo de seu estudo consistia em avaliar 
a ordem de grandeza dos valores envolvidos.

Apesar disso, o trabalho de Harberger (1954) foi alvo de críticas, principalmente em relação ao pressuposto de que $\eta=1$ para todas as indústrias; isto é, o autor não considerou a interdependência de $\Delta \mathrm{p}$ e $\Delta \mathrm{q}$. Além disso, também foi criticado por procedimentos de estimações sobre o excesso de lucro.

Daskin (1991) sugeriu uma reformulação na equação original que retratava a perda de bemestar em uma estrutura de monopólio. Por meio dessa proposta, tornou-se possível mensurar a perda de bem-estar em outras estruturas de mercado, como oligopólios e para demandas que não apresentavam necessariamente unitárias, chegando à Equação (3).

$D W L=\left(\frac{1}{2}\right) \pi^{2} \frac{\eta}{R}$

em que, $\eta$ representa a elasticidade-preço da demanda em valor absoluto; $\pi$, o lucro do monopolista; e $\mathrm{R}$, a receita total, em que $\mathrm{R}=\mathrm{P}^{*} \mathrm{Q}$.

Considerando um contexto de oligopólio, existem métodos distintos utilizados para mensurar a perda de bem-estar dos consumidores devido ao exercício de poder de mercado em estruturas de competição imperfeita. Especificamente, Dixit e Stern (1982) e Clarke e Davies (1982), buscaram mensurar a perda de bem-estar em uma estrutura oligopolista por meio de um método fundamentado na parametrização específica das conjecturas de uma firma oligopolista. Entretanto, por causa da indisponibilidade de dados desagregados em nível de firmas, alguns estudos quanto ao DWL que poderiam envolver vários setores da economia, muitas vezes mostram-se inviáveis.

Conforme Mas Collel et al. (1995), a definição do DWL é a redução do bem-estar gerada por meio da distorção da quantidade com respeito ao equilíbrio competitivo. Desta forma, considerando $\mathrm{Q}(\mathrm{P})$ como a função de demanda e Cmg o custo marginal da indústria, o DWL pode ser definido, matematicamente, como apresentado na Equação (4).

$$
D W L=\int_{P_{C P}}^{P_{0}}\{Q(P)-C m g[Q(P)]\} d P
$$

Observa-se que a primeira parte da integral representada na Equação (4) é referente ao excedente do consumidor (EC), e a segunda, ao excedente do produtor (EP). A diferença entre as duas partes permite identificar o DWL, assim, DWL=EC-EP. Para mensurar o EC, define-se previamente uma função de demanda e estima-se sua elasticidade-preço $(\varepsilon)$. Com isso, o EC e EP podem ser representados, respectivamente, pelas Equações (5) e (6).

$E C=\frac{R T(Q)_{0}}{(1-\varepsilon)}\left[1-\left(1-L_{i}\right)^{(1-\varepsilon)}\right]$

$E P=R T(Q) * \sum_{i=1}^{N} L_{i} * S_{i}$

em que, $\mathrm{RT}(\mathrm{Q})$ corresponde a receita total em um mercado oligopolista e, $\mathrm{L}_{\mathrm{i}}$ é o Índice de Lerner. Daskin (1991) concluiu que, quando o equilíbrio é o de concorrência perfeita $\left(\mathrm{Q}_{\mathrm{CP}}, \mathrm{P}_{\mathrm{CP}}\right)$, e $\mathrm{L}_{\mathrm{i}}=0, \forall$ $\mathrm{i}=1, \mathrm{~N}, \mathrm{EP}=0$. Quando a análise é feita em um mercado oligopolista $\left(\mathrm{Q}_{\mathrm{o}}, \mathrm{P}_{\mathrm{o}}\right), \mathrm{EC}=0$. 


\section{METODOLOGIA}

A seção de metodologia está dividida em três subseções: a primeira, que trata de medidas de concentração, a segunda, que fala dos procedimentos econométricos realizados no trabalho, e a última em que a base de dados utilizada é apresentada.

\subsection{Medidas de concentração de Mercado}

Com o objetivo de mensurar possíveis perdas de bem-estar social (DWL), é necessário, em primeiro lugar, medir a concentração do mercado. Para tanto, existem alguns índices que foram utilizados. O primeiro, trata-se da razão de concentração $\left(\mathrm{CR}_{\mathrm{k}}\right)$, em que k define o número de empresas para o qual o índice de concentração é mensurado, sendo geralmente, utilizadas as quatro maiores $(\mathrm{k}=4)$ ou com as oito maiores $(\mathrm{k}=8)$ empresas do setor, segundo Comunello e Godarth (2014) e Resende (1994).

Destaca-se que o resultado do $\mathrm{CR}_{\mathrm{k}}$ deve variar de 0 (zero) a 1 (um), em que zero representa concorrência perfeita, devido à existência de diversos competidores e a participação pequena de cada um. Já o extremo oposto, ou seja, quanto mais próximo de um, indica a existência de uma alta concentração do mercado analisado, próxima à situação de monopólio. $\mathrm{O}$ cálculo deste índice é realizado pela somatória da participação do mercado das k maiores empresas. Observa-se que a participação de cada empresa é obtida pela divisão da parcela que esta tem no mercado pelo volume total no mercado. A partir do resultado encontrado, é possível classificar o mercado quanto ao seu grau de concentração, conforme exposto no Quadro 1.

$\mathrm{O}$ índice razão de concentração $\left(\mathrm{CR}_{\mathrm{k}}\right)$ permite medir o nível de concentração e classificar a condição do mercado em estudo; porém, de acordo com Resende (1994), existem alguns pontos negativos em relação à aplicação de tal medida, a saber: considera apenas as k maiores firmas, apesar destas estarem expostas a variações, o que impossibilita uma demonstração do nível de concentração relativa; e, também este indicador não distingue o tamanho de cada empresa que é utilizada no cálculo, o que pode gerar problemas nas análises, uma vez que é possível que as empresas apresentem grandes diferenças de tamanho.

Quadro 1- Classificação da concentração de mercado considerando os valores de $C R_{k}$

\begin{tabular}{|c|c|c|}
\hline $\begin{array}{c}\text { Parcela de Mercado das } 4 \\
\text { maiores empresas }\end{array}$ & $\begin{array}{c}\text { Parcela de mercado das } 8 \\
\text { maiores empresas }\end{array}$ & $\begin{array}{c}\text { Classificação de mercado } \\
\text { quanto ao }\left(C R_{k}\right)\end{array}$ \\
\hline $75 \%$ ou mais & $90 \%$ ou mais & Muito Alto \\
\hline $65 \%-75 \%$ & $85 \%-90 \%$ & Alto \\
\hline $50 \%-65 \%$ & $70 \%-85 \%$ & Moderadamente Alto \\
\hline $35 \%-50 \%$ & $45 \%-70 \%$ & Moderadamente Baixo \\
\hline $35 \%$ ou menos & $45 \%$ ou menos & Baixo \\
\hline
\end{tabular}

Fonte: Adaptado de Almeida e Silva (2017).

Outro índice que permite mensurar a concentração de mercado é o Índice de HirschsmanHerfindahl (HHI) que, conforme CADE (2016), refere-se à soma dos quadrados da participação de uma firma no mercado. Ou seja, visa corrigir uma das limitações vistas no índice de razão de concentração. E para a mensuração desse índice, é necessário qualquer variável que possa representar a firma. A representação matemática do HHI é dada conforme Equação (7):

$H H I=\sum_{i}^{k}(P i)^{2}$

em que, k é a quantidade de empresas no mercado e $\mathrm{P}_{\mathrm{i}}$ é a participação da empresa de ordem 
i no mercado. Ao elevar cada parcela de mercado ao quadrado, dá-se importância maior para uma empresa maior; ou seja, reduz-se o problema visto no índice de razão de concentração. Como o HHI é calculado utilizando o Market share ao quadrado, seus valores estão entre 0 e 10.000 pontos. De acordo com CADE (2016), um mercado é considerado altamente concentrado quando seu HHI está acima de 2500 pontos, sendo considerado moderadamente concentrado se o $\mathrm{HHI}$ está entre 1500 e 2500 pontos e não concentrado para valores abaixo de 1500 pontos.

Outra forma de analisar é dividindo os valores encontrados por 10.000. Os resultados do HHI devem variar entre $1 / \mathrm{n}$ até 1 (um), em que o valor de $1 / \mathrm{n}$ pode ser 0 (zero) e demonstraria uma situação de concorrência perfeita, e um resultado próximo a 1 (um) indicaria uma situação de mercado muito concentrado. Neste caso, apresenta-se a classificação do mercado de acordo com os resultados que podem ser obtidos pelo cálculo do HHI, sugerido por Almeida e Silva (2017).

Quadro 2- Classificação do mercado de acordo com os valores do índice HHI

\begin{tabular}{|c|c|}
\hline HHI & Classificação do mercado \\
\hline Inferior a 0,1 & Indústria pouco concentrada \\
\hline Entre 0,1 e 0,18 & Indústria com concentração moderada \\
\hline Superior a 0,18 & Indústria muito concentrada \\
\hline
\end{tabular}

Fonte: Adaptado de Almeida e Silva (2017).

Quanto às críticas do HHI, para CADE (2016), é possível que ele não mensure adequadamente o poder de mercado em algumas situações, como quando os agentes são coordenados, se uma empresa apresenta estratégia disruptiva, dentre outros.

\subsection{Modelos de dados em painel e os procedimentos econométricos para a estimação da elasticidade preço demanda.}

Para a modelagem, necessária para a mensuração do peso morto, foram utilizados modelos de dados em painel, pois, conforme Gujarati (2011), este modelo permite acompanhar ao longo do tempo o movimento de unidades de cortes transversais, o que implica em maior número de observações e maior eficiência das estimativas.

Para a estimativa, parte-se de um conjunto de dados de unidades (i) e período de tempo (t). $\mathrm{Na}$ equação (8), apresenta-se a fórmula geral para aplicação desse modelo.

$Y_{i t}=\alpha_{i t}+X^{\prime}{ }_{i t} \beta+\varepsilon_{i t}$

em que, $Y_{\text {it }}$ seria a variável dependente, o termo $\alpha_{i t}$ seria o intercepto, $X^{\prime}{ }_{i t}$ as variáveis explicativas e $\beta$ é um vetor de coeficientes angulares estimados.

A partir disso, pode-se aplicar à Equação (8) dois métodos diferentes de estimação, que são os modelos de efeitos fixos e os modelos de efeitos aleatórios. Ressalta-se que, segundo Wooldridge (2017), o modelo de efeitos aleatórios é mais indicado quando o $\alpha_{\text {it }}$ não apresenta correlação com as variáveis explicativas; já o modelo de efeitos fixos se adequa melhor quando $\alpha_{\mathrm{it}}$ apresenta correlação com as variáveis explicativas. Outro modelo comumente estimado quando no contexto de dados em painel é o de Mínimos Quadrados Agrupados ou pooled, em que, todas as observações são utilizadas sem nenhuma referência ao tempo ou a unidade observacional, neste sentido, sendo calculado com os estimadores usuais de Mínimos Quadrados Ordinários.

Para definir qual o modelo mais adequado, é necessário realizar o teste de Chow, que compara o modelo pooled com o de efeitos fixos; o teste de Hausman, que relaciona o modelo de efeitos aleatórios contra a hipótese alternativa de que o melhor modelo é o de efeitos Fixos; e, por fim, o teste do multiplicador de Lagrange de Breusch -Pagan (LM teste), que realiza a comparação entre o modelo pooled e o de efeitos aleatórios. 
Também é necessário verificar se os resultados estimados atendem às premissas da ausência de autocorrelação, heterocedasticidade e multicolinearidade, sendo esta última, pouco comum, pela própria estrutura dos dados em painel. Para tanto, no que diz respeito à identificação da autocorrelação, geralmente, aplica-se o teste de autocorrelação serial de Wooldridge. Para testar a presença de heterocedasticidade no modelo, utiliza-se o teste de Wald. Também é necessário verificar se os resíduos da regressão se distribuem de forma normal. Também é preciso verificar se as variáveis são estacionárias, realizando teste de raiz unitária aplicados a dados em painel.

Neste estudo, com vistas a obter as relações entre a quantidade demanda de carros 1000 cilindradas e seus principais determinantes, foi realizada a estimação de uma função de demanda. Optou-se por utilizar a forma funcional logaritimizada (ln-ln),pois ela permite a análise dos coeficientes estimados em termos de elasticidades. Destaca-se que a escolha do modelo ln-ln deverá ter respaldo nos resultados da aplicação do teste Reset, que auxilia na escolha do melhor modelo a ser utilizado. Assim, a demanda que se estimou neste estudo está representada na Equação (9).

$L n Q_{i t}=\beta_{0}+\beta_{1} L n P M_{i t}+\beta_{2} L n S M R_{i t}+\beta_{3} L n G_{i t}+\beta_{4} L n L 2 . P M_{i t}+\beta_{5} L n L 2 . Q_{i t}+u_{i t}$

em que a quantidade vendida de carros 1000 cilindradas (Q) seria a variável explicada, e as variáveis preço médio do objeto de estudo (PM), salário médio real (SMR) e gasolina (G) seriam as variáveis explicativas. Os coeficientes $\beta_{0}, \beta_{1} \beta_{2}, \beta_{3}, \beta_{4}$ e $\beta_{5}$ são os parâmetros a serem estimados; $L_{2}$ refere-se à segunda defasagem da variável, pois os preços médios do passado podem determinar o comportamento da demanda no tempo presente, o mesmo ocorre com a própria quantidade demandada; e, $\mathrm{u}_{\mathrm{it}}$, é o termo de erro estocástico do modelo.

Por fim, dadas as considerações teóricas em relação ao comportamento da demanda e também aos possíveis métodos de estimação, cabe epilogar as relações que se esperam obter a partir dos parâmetros estimados conforme o modelo apresentado na Equação (9). Assim, no Quadro (3), apresentam-se as relações para os parâmetros estimados, considerando a Lei da Demanda.

Quadro 3- Relação entre os determinantes da demanda e quantidade demandada de carros 1000 cilindradas no Brasil, para o período de 2005 a 2014.

\begin{tabular}{|c|c|c|}
\hline Parâmetros & $\begin{array}{c}\text { Sinal } \\
\text { esperado }\end{array}$ & Interpretação \\
\hline $\boldsymbol{\beta}_{0}$ & + & $\begin{array}{l}\text { Quantidade média vendida de carros } 1000 \text { cilindradas, tudo mais } \\
\text { mantido constante. }\end{array}$ \\
\hline$\beta_{1}$ & - & $\begin{array}{l}\text { O aumento do preço médio do carro } 1000 \text { cilindradas tende a } \\
\text { reduzir a quantidade vendida de carros } 1000 \text { cilindradas, tudo } \\
\text { mais mantido constante. }\end{array}$ \\
\hline $\boldsymbol{\beta}_{2}$ & + & $\begin{array}{l}\text { Quanto maior o salário médio real do indivíduo, maior será a } \\
\text { quantidade vendida de carros } 1000 \text { cilindradas, tudo mais } \\
\text { mantido constante. }\end{array}$ \\
\hline$\beta_{3}$ & - & $\begin{array}{l}\text { Quanto maior for o preço da gasolina, menor será a quantidade } \\
\text { vendida de carros } 1000 \text { cilindradas, tudo mais mantido } \\
\text { constante, visto que a gasolina é considerada um bem } \\
\text { complementar ao carro. }\end{array}$ \\
\hline
\end{tabular}

Fonte: Elaboração própria.

\subsection{Procedimentos para identificação da perda de bem-estar (DWL)}

Na possibilidade da presença do exercício do poder de mercado, pode-se verificar as perdas geradas por esse possível exercício do poder de mercado para a sociedade de modo geral. Nestas circunstâncias, o cálculo do DWL é extremamente útil, pois permite quantificar as perdas, em termos monetários, que os consumidores daquele mercado relevante sofrem em virtude do exercício do poder de mercado de uma empresa ou de empresas. As perdas de bem-estar são obtidas pela diferença entre os excedentes do consumidor e produtor. Matematicamente, o cálculo do DWL seguirá a metodologia 
adotada no estudo de Schmidt e Lima (2006) que se basearam em Daskin (1991).

Ressalta-se que o fato de que para os casos de oligopólios com produtos homogêneos, as firmas se aproximam de um comportamento de concorrência perfeita e, neste caso, a variação da conjectura representada por $\alpha_{\mathrm{i}}$ é zero; portanto, o índice de Lerner antes representado por: $L_{i}=$ $\frac{s_{i}\left(1-\propto_{i}\right)+\alpha_{i}}{\varepsilon}$ agora pode ser reescrito como na Equação (10).

$\mathrm{L}_{\mathrm{i}}=\frac{\mathrm{S}_{\mathrm{i}}}{\varepsilon}$

Daskin (1991) destacou também o fato do excedente do produtor não necessariamente requerer informação a respeito da parcela ou margens preço-custo de uma firma individual. Neste aspecto, a sugestão é utilizar a parcela de mercado de uma média ponderada das maiores empresas. Em seu trabalho, Daskin (1991) optou pelas quatro maiores empresas. Neste estudo foram utilizadas as cinco principais montadoras que atuam no Brasil, a saber: a General Motors, Ford, Renault, Fiat e Volkswagen e seus respectivos modelos: Celta, Ka, Clio, Uno Gol e também a soma das suas parcelas de mercado $\left(\mathrm{S}_{5}\right)$ durante o período de 2005 a 2014. Desta forma, as equações do excedente do consumidor (EC) e excedente do produtor (EP) podem ser reescritas como em (11) e (12), respectivamente.

$$
\begin{aligned}
& \mathrm{EC}=\frac{\mathrm{RT}(\mathrm{Q})_{0}}{(1-\varepsilon)} *\left[1-\left(1-\frac{\mathrm{S}_{5}}{\varepsilon}\right)^{(1-\varepsilon)}\right] \\
& \mathrm{EP}=\mathrm{RT}(\mathrm{Q})_{0} * \sum_{\mathrm{i}=1}^{\mathrm{N}} \frac{\mathrm{S}_{5}}{\varepsilon} * \mathrm{~S}_{5}
\end{aligned}
$$

E, de posse desses valores, mensurar a perda de peso morto conforme Equação (13).

$\mathrm{DWL}=\left\{\frac{\mathrm{RT}(\mathrm{Q})_{0}}{(1-\varepsilon)} *\left[1-\left(1-\frac{\mathrm{S}_{5 \mathrm{i}}}{\varepsilon}\right)^{(1-\varepsilon)}\right]-\mathrm{RT}(\mathrm{Q})_{0} * \sum_{\mathrm{i}=1}^{\mathrm{N}} \frac{\mathrm{S}_{5 \mathrm{i}}}{\varepsilon} * \mathrm{~S}_{5 \mathrm{i}}\right\}$

\subsection{Descrição das variáveis e fonte de dados}

As informações para a obtenção das medidas de concentração e também para a as estimações econométricas utilizaram dados mensais de corte transversal do segmento de automóveis licenciados de 1000 cilindradas no Brasil no período de 2005 a 2014. As séries de quantidade de carros 1000 cilindradas vendidos no Brasil no período de análise foram obtidas no site da Associação Nacional dos Fabricantes de Veículos Automotores (ANFAVEA), sendo selecionadas todas as montadoras disponíveis para o cálculo do total de mercado. Para a análise mais detalhada, foram utilizadas as cinco maiores montadoras que se encontram no país: Ford, Volkswagen, General Motors, Fiat e Renault.

Para a variável preço, que não é disponibilizada pela ANFAVEA, utilizou-se os dados da Fundação Instituto de Pesquisa Econômicas (FIPE), que informou o preço médio praticado no mercado. Quanto à renda, adotou-se o salário médio real do Brasil obtido no site do Instituto de Pesquisa Econômica Aplicada (IPEA). Por fim, cabe dizer que para o cálculo das medidas de concentração e do DWL, utilizou-se o pacote Excel e para a estimação da Equação (12) e realização dos testes econométricos associados a ela, utilizou-se o software Stata 12.

\section{RESULTADOS E DISCUSSÕES}

\subsection{Análise da concentração de mercado no segmento de carros 1000 cilindradas no Brasil}

Antes de apresentar a discussão sobre a concentração do mercado é necessária a definição do mercado relevante que deve observar as condições técnico-econômicas estruturais nas quais o 
exercício do poder de mercado, tanto em relação ao preço quanto em relação a quantidade, seja plausível.

Nesta pesquisa, considera-se o Brasil como mercado relevante por conta do grande impacto que a indústria automobilística tem sobre a economia brasileira e também por haver montadoras em diversas regiões do país; além do fato de que os carros importados não serem considerados substitutos dos carros populares (1000 cilindradas) devido às significativas diferenças de valores. Já a escolha pelo segmento de 1000 cilindradas ocorreu uma vez que tais produtos, apesar de apresentar suaves diferenças de designs e marca, tem características técnicas muito semelhantes, e são o tipo de veículo mais vendido no Brasil.

Ressalta-se que, mesmo com a entrada no setor automobilístico de montadoras estrangeiras, como Hyundai, Nissan, Citroën, Peugeot, Kia, Chery, JAC, entre outras, estas, durante o período de estudo, não ofereciam carros que competissem com os de 1000 cilindradas das cinco montadoras seleciondas: seja em preço, ou por questões de potência de motor, muitas dessas não possuem carros 1000 cilindradas, por padrões de qualidade ou ainda por diferenças em acessórios e design.

Definido o mercado relevante, passa-se a tratar da concentração de mercado em si. Para tanto, calculou-se o grau de concentração de mercado para o segmento de carros 1000 cilindradas, considerando todas as montadoras do Brasil. As informações foram as quantidades de carros licenciados, disponibilizadas pela ANFAVEA. Nota-se que as cinco maiores: Fiat, General Motors (GM), Volkswagen (VW), Ford e Renault, apresentam quase que a totalidade do mercado. Os resultados para $\mathrm{o}_{5}$ foram apresentados na Tabela (1).

Tabela 1- Market Share das cinco maiores empresas do segmento de carros 1000 cilindradas no Brasil, 2005 a $2014(\%)$

\begin{tabular}{ccccccc}
\hline Empresa /Ano & Fiat & GM & VW & Ford & Renault & CR5 \\
\hline 2005 & $32,11 \%$ & $29,26 \%$ & $21,87 \%$ & $10,69 \%$ & $2,93 \%$ & $\mathbf{9 6 , 8 6 \%}$ \\
2006 & $33,66 \%$ & $27,06 \%$ & $25,28 \%$ & $10,11 \%$ & $1,18 \%$ & $\mathbf{9 7 , 2 8 \%}$ \\
2007 & $37,86 \%$ & $19,54 \%$ & $27,10 \%$ & $11,25 \%$ & $1,92 \%$ & $\mathbf{9 7 , 6 7 \%}$ \\
2008 & $33,45 \%$ & $19,36 \%$ & $29,16 \%$ & $12,41 \%$ & $3,38 \%$ & $\mathbf{9 7 , 7 6 \%}$ \\
2009 & $33,59 \%$ & $18,65 \%$ & $34,19 \%$ & $8,09 \%$ & $3,47 \%$ & $\mathbf{9 8 , 0 0 \%}$ \\
2010 & $29,34 \%$ & $24,78 \%$ & $32,44 \%$ & $6,73 \%$ & $4,68 \%$ & $\mathbf{9 7 , 9 8 \%}$ \\
2011 & $33,33 \%$ & $24,51 \%$ & $28,43 \%$ & $9,80 \%$ & $1,96 \%$ & $\mathbf{9 8 , 0 3 \%}$ \\
2012 & $33,32 \%$ & $24,50 \%$ & $28,42 \%$ & $9,80 \%$ & $1,96 \%$ & $\mathbf{9 8 , 0 1 \%}$ \\
2013 & $33,27 \%$ & $24,46 \%$ & $28,38 \%$ & $9,79 \%$ & $1,96 \%$ & $\mathbf{9 7 , 8 5 \%}$ \\
2014 & $33,14 \%$ & $24,37 \%$ & $28,27 \%$ & $9,75 \%$ & $1,95 \%$ & $\mathbf{9 7 , 4 8 \%}$ \\
\hline
\end{tabular}

Fonte: Elaboração própria a partir dos dados de pesquisa.

Conforme resultados apresentados na Tabela (1), considerando as maiores empresas do setor, observou-se um $\mathrm{CR}_{5}>90 \%$. Assim, de acordo com Comunello e Godarth (2014) e Resende (1994) pode-se dizer que este mercado apresenta sinais de uma estrutura altamente concentrada.

Além disso, conforme Vieira, Andrade, Harder e Del Corso (2008) a razão da concentração não sofreu influência alguma das empresas que entraram no mercado após o ano de 1995 até 2005 . Tal situação é demonstrada também na Tabela (1), em que se notou que, ao longo do período de análise (2005 a 2014), o segmento de carros 1000 cilindradas continuou apresentando características semelhantes em relação ao grau de concentração, inclusive, na comparação entre início e final de período, com aumento da concentração.

Nota-se ainda que as três maiores empresas - Fiat, General Motors e Volkswagen apresentam 
uma participação similar e, sozinhas, detinham mais de 70\% do mercado. Pode-se visualizar que a Fiat é a que apresenta a maior participação, com exceção do ano de 2010, onde a Volkswagen apresenta uma participação três pontos percentuais superior.

Apesar dos resultados encontrados pelo $\mathrm{CR}_{5}$, é importante olhar também para o $\mathrm{HHI}$, que visa reduzir as limitações apresentadas no cálculo do $\mathrm{CR}_{5}$. Na Tabela (2), apresentam-se os resultados obtidos para o HHI, calculados para o segmento de carros 1000 cilindradas no Brasil, no período de 2005 a 2014.

Tabela 2 - Índice de concentração de mercado HHI das cinco maiores empresas do segmento de carros 10000 cilindradas no Brasil, 2005 a 2014.

\begin{tabular}{ccccccc}
\hline Empresa /Ano & GM & RENAULT & VOLKS & FORD & FIAT & HHI \\
\hline 2005 & 0,09 & 0,00 & 0,05 & 0,01 & 0,10 & $\mathbf{0 , 2 5}$ \\
2006 & 0,07 & 0,00 & 0,06 & 0,01 & 0,11 & $\mathbf{0 , 2 6}$ \\
2007 & 0,04 & 0,00 & 0,07 & 0,01 & 0,14 & $\mathbf{0 , 2 7}$ \\
2008 & 0,04 & 0,00 & 0,09 & 0,02 & 0,11 & $\mathbf{0 , 2 5}$ \\
2009 & 0,03 & 0,00 & 0,12 & 0,01 & 0,11 & $\mathbf{0 , 2 7}$ \\
2010 & 0,06 & 0,00 & 0,11 & 0,00 & 0,09 & $\mathbf{0 , 2 6}$ \\
2011 & 0,06 & 0,00 & 0,08 & 0,01 & 0,11 & $\mathbf{0 , 2 6}$ \\
2012 & 0,06 & 0,00 & 0,08 & 0,01 & 0,11 & $\mathbf{0 , 2 6}$ \\
2013 & 0,06 & 0,00 & 0,08 & 0,01 & 0,11 & $\mathbf{0 , 2 6}$ \\
2014 & 0,06 & 0,00 & 0,08 & 0,01 & 0,11 & $\mathbf{0 , 2 6}$ \\
\hline
\end{tabular}

Fonte: Elaboração própria a partir dos dados de pesquisa.

De acordo com os resultados apresentados na Tabela (2), o índice HHI encontra-se maior do que $(0,18) 18 \%$, o que indica que o mercado é altamente concentrado, e isso se mantém ao longo dos anos. De acordo com os parâmetros do CADE (2016), os valores de HHI sugerem também uma concentração alta.

Com vistas a comparar a concentração de mercado, tanto pelo CR5 quanto pelo HHI, ao longo do período de análise, apresenta-se na Figura (1) o comportamento dessas medidas de concentração para o segmento de carros 1000 cilindradas no Brasil de 2005 a 2014.

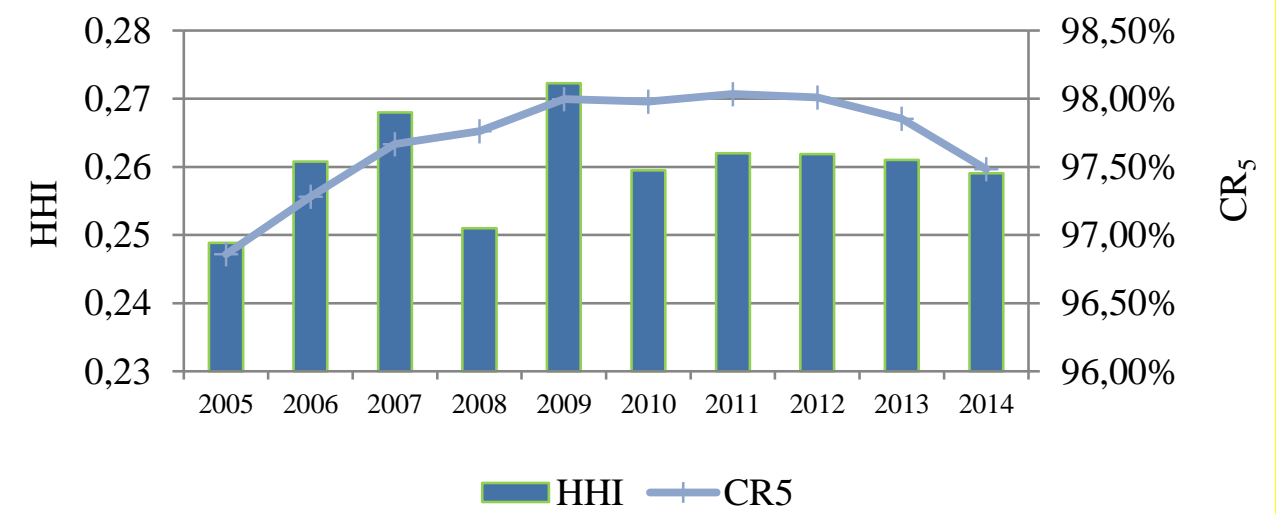

Figura 1- Comportamento do CR5 e do HHI para o segmento de carros 1000 cilindradas no Brasil, 2005 a 2014

Fonte: Elaboração própria a partir dos resultados da pesquisa. 
Conforme pode-se observar pela análise da Figura (1), o segmento de carros 1000 cilindradas no Brasil, para o período de 2005 a 2014, considerando o $\mathrm{CR}_{5}$ apresentou-se pouco dinâmico, uma vez que o nível do $\mathrm{CR}_{5}$ se manteve entre $96 \%$ a $98,20 \%$; ou seja, o mercado se mostrou em uma situação de oligopólio concentrado por ao menos 10 anos. E também se notou que, mesmo com oscilações, o HHI se manteve acima de 0,18 (18\%) durante todos os anos estudados, o que confirma a situação de mercado altamente concentrado.

\subsection{Mensuração e avaliação do comportamento da demanda no segmento de carros 1000 cilindradas no Brasil}

As estatísticas descritivas para as informações utilizadas no modelo econométrico estão descritas na Tabela (3). Nela, a quantidade de carros é definida por Q, PM é o preço médio do carro 1.000 cilindradas, SMR é o salário mínimo real e G é o preço da gasolina. As informações são completas no período e nas unidades de análise, ou seja, o painel é balanceado.

Tabela 3- Estatística descritiva das variáveis utilizadas na estimação da demanda por carros 1000 cilindradas no Brasil, para o período de 2005 a 2014

\begin{tabular}{cccccc}
\hline Variável & Observações & Média & Erro padrão & Mínimo & Máximo \\
\hline SMR & 580,00 & 754,78 & 4,35 & 514,98 & 917,89 \\
PM & 580,00 & $30.432,27$ & 0,09 & 24,21 & 39,22 \\
Q & 580,00 & $17.464,00$ & 475,95 & 275,00 & 45444,00 \\
G & 580,00 & 2,61 & 0,01 & 2,26 & 2,99 \\
\hline
\end{tabular}

Fonte: Elaboração própria a partir dos dados da pesquisa.

Nota: Q representa a quantidade de carros 1000 cilindradas vendidas; PM é o preço médio do carro 1000 cilindradas; SMR é o salário mínimo real; G é o preço da gasolina.

De acordo com os resultados apresentados na Tabela (3), pode-se observar que o preço médio dos carros 1000 cilindradas no Brasil é de $\mathrm{R} \$ 30.432,27$; isto é, cerca de 40 vezes maior do que o salário mínimo real médio do período. Ressalta-se que se trata de um tipo de carro mais popular, cujo preço é o mais baixo. Além disso, mesmo que as famílias brasileiras tenham dificuldade em adquirir esse tipo de bem, ainda assim a receita gerada pelo setor automobilístico, especificamente com as vendas do segmento de carros 1000 cilindradas foi de $\mathrm{R} \$ 531,480,118.90$, em média, no período, conforme informações da Tabela (3).

O teste de raiz unitária de Harris-Tzavalis foi utilizado, para confirmar a estacionariedade, mostrando que todas as séries são estacionárias em nível (APÊNDICE A). Foram aplicados os testes de Chow e de Hausman (APÊNDICE B), não sendo necessário utilizar o teste LR uma vez que o modelo de efeitos fixos se mostrou superior tanto ao modelo pooled quanto ao modelo de efeitos aleatórios. Os resultados foram apresentados na Tabela (4). 
Tabela 4 - Coeficientes estimados por EF para a equação de demanda por automóveis 1000 cilindradas no Brasil, para o período de 20005 a 2014.

\begin{tabular}{ccccc}
\hline & Coeficiente & Erro Padrão & T & p-valor \\
\hline Constante & $-1,8273$ & 2,4716 & $-0,7400$ & 0,5010 \\
SMR & 1,1771 & 0,2899 & 4,0600 & 0,0150 \\
G & $-0,7021$ & 0,6714 & $-1,0500$ & 0,3550 \\
L2. PM & 0,8796 & 0,5196 & 1,6900 & 0,1660 \\
L2. Q & 0,4474 & 0,1216 & 3,6800 & 0,0210 \\
\hline R2 & 0,86 & & & \\
\hline
\end{tabular}

Fonte: Elaboração própria a partir dos dados de pesquisa.

Nota: PM é o preço médio dos carros 1000 cilindradas; SMR é o salário médio real; G é o preço médio da Gasolina e L2 significa que a variável foi defasada em dois períodos.

A partir dos resultados apresentados na Tabela (4), notou-se que todos os coeficientes estimados foram estatisticamente significativos a pelo menos $10 \%$ de significância, com exceção do coeficiente estimado para as variáveis preço da gasolina $(\mathrm{G})$, o preço médio do carro na sua segunda defasagem (L2.PM) e a constante. Quanto ao ajuste do modelo, observou-se que $86 \%$ das variações na quantidade demandada (vendida) de carros 1000 cilindradas no Brasil são explicadas por variações nas variáveis explicativas do modelo. Além disso, os sinais dos coeficientes estimados apresentaramse em conformidade com a lei da demanda.

Quanto à magnitude dos coeficientes estimados, notou-se que dado um aumento de uma unidade percentual no preço, a quantidade demanda de carros 1000 cilindradas no Brasil, de 2005 a 2014, diminuiu em $0,94 \%$, com tudo mais mantido constante. Também pode-se dizer que dado um aumento de uma unidade percentual no salário médio real, a quantidade consumida de carros 1000 cilindradas aumentou em $1,17 \%$, com tudo mais mantido constante.

Por fim, considerando a magnitude do coeficiente estimado para o preço, medida da elasticidade-preço da demanda, pode-se afirmar que a demanda por automóveis 1000 cilindradas no Brasil, para o período de 2005 a 2014 foi inelástica, uma vez que seu valor absoluto é inferior a um.

\subsection{Análise da perda de bem-estar social (DWL) no mercado de carros 1000 cilindradas no Brasil.}

Até este ponto, de acordo com as seções 4.1 e 4.2 verifica-se que o mercado de carros de 1000 cilindradas de 2005 a 2014 é altamente concentrado, de acordo com o CR5 e HHI; e, que a demanda é inelástica ao preço. Logo, esses dois elementos podem levar a suspeitar de incentivos para a realização de exercício do poder de mercado. Caso haja exercício de poder de mercado, é possível que haja a perda de peso morto, e esta seção expõe os resultados de tal cálculo.

Para o cálculo do DWL para o setor automobilístico brasileiro, especificamente para o segmento de carros 1000 cilindradas, considerando o período de 2005 a 2014, optou-se por utilizar a receita das cinco maiores montadoras do mercado, de forma combinada. Ou seja, a receita total do setor, que foi dada pela soma simples das receitas obtidas pelas cinco montadoras para cada ano da análise.

Além disso, tal metodologia é adequada, uma vez que a estimação da equação de demanda (Equação 9) foi realizada por modelos de dados em painel (combinados) o que gera apenas uma estimativa média da elasticidade-preço da demanda $(-0,94)$, essencial ao cálculo do DWL, como visto na seção 3.3. Assim, os resultados obtidos para o DWL foram apresentados na Tabela (5). 
Tabela 5 - Resultado para o DWL, considerando a receita total do segmento de carros 1000 cilindradas no Brasil, a cada ano, no período de 2005 a 2014.

\begin{tabular}{cccc}
\hline Ano & Excedente do Consumidor & Excedente do Produtor & DWL \\
\hline 2005 & $28.657 .467,16$ & $1.768 .561,18$ & $26.888 .905,98$ \\
2006 & $35.608 .129,76$ & $2.206 .497,95$ & $33.401 .631,82$ \\
2007 & $42.590 .544,87$ & $2.649 .064,42$ & $39.941 .480,45$ \\
2008 & $46.013 .082,90$ & $2.864 .522,93$ & $43.148 .559,97$ \\
2009 & $49.676 .956,37$ & $3.099 .566,55$ & $46.577 .389,82$ \\
2010 & $49.653 .448,83$ & $3.097 .572,77$ & $46.555 .876,07$ \\
2011 & $51.495 .166,02$ & $3.214 .206,03$ & $48.280 .959,99$ \\
2012 & $47.210 .372,82$ & $2.946 .016,49$ & $44.264 .356,33$ \\
2013 & $44.940 .739,14$ & $2.800 .234,79$ & $42.140 .504,36$ \\
2014 & $41.182 .058,91$ & $2.556 .931,07$ & $38.625 .127,83$ \\
\hline
\end{tabular}

Fonte: Elaboração própria a partir dos dados da pesquisa.

Conforme resultados apresentados na Tabela (5), observou-se que o DWL apresentou, para todos os períodos analisados, valores positivos, isto implica em dizer que as empresas Ford, Chevrolet, Fiat, Volkswagen e Renault, operando no segmento de mercado de veículos de 1000 cilindradas, provocaram um peso morto para a sociedade na ordem de 40 bilhões ao ano.

De acordo com os valores encontrados, é notável a magnitude desse peso morto que a indústria automobilística, mais especificamente, o setor de carros 1000 cilindradas impôs sobre o bem-estar social na economia brasileira, no período de 2005 a 2014. O valor é tão alto que chega a ser maior do que o produto interno bruto (PIB) de diversos estados do país, como: Acre, Alagoas, Amapá, Maranhão, Mato Grosso do Sul, Paraíba, Piauí, Rio Grande do Norte, Rondônia, Roraima, Sergipe e Tocantins.

A título de ilustração, no intuito de melhor representar a magnitude do DWL calculado nesta pesquisa, apresentou-se na Tabela (6) um comparativo entre o peso morto, DWL, e o PIB do estado Rio Grande do Norte.

Tabela 6 - Comparação entre o PIB do Rio Grande do Norte e o DWL, no período de 2005 a 2014.

\begin{tabular}{ccccc}
\hline Ano & PIB $(\mathbf{R N})$ & DWL & PIB RN/DWL & 1- PIB/DWL \\
\hline 2005 & $17.869 .513,48$ & $26.888 .905,98$ & $66 \%$ & $34 \%$ \\
2006 & $20.554 .625,32$ & $33.401 .631,82$ & $62 \%$ & $38 \%$ \\
2007 & $22.925 .558,53$ & $39.941 .480,45$ & $57 \%$ & $43 \%$ \\
2008 & $25.481 .444,62$ & $43.148 .559,97$ & $59 \%$ & $41 \%$ \\
2009 & $27.904 .988,65$ & $46.577 .389,82$ & $60 \%$ & $40 \%$ \\
2010 & $32.338 .894,71$ & $46.555 .876,07$ & $69 \%$ & $31 \%$ \\
2011 & $36.103 .201,63$ & $48.280 .959,99$ & $75 \%$ & $25 \%$ \\
2012 & $39.543 .678,54$ & $44.264 .356,33$ & $89 \%$ & $11 \%$ \\
2013 & $43.312 .017,82$ & $42.140 .504,36$ & $103 \%$ & $-03 \%$ \\
2014 & $47.439 .463,33$ & $38.625 .127,83$ & $123 \%$ & $-23 \%$ \\
\hline
\end{tabular}

Fonte: Elaboração própria a partir dos resultados da pesquisa.

Conforme Tabela (6) pode-se afirmar que o DWL excede o PIB do Rio Grande do Norte em $34 \%$ no primeiro ano, por exemplo. Além disso, destaca-se que durante o período da análise, o PIB do Rio Grande do Norte mais que dobra, e o DWL apresenta crescimento durante oito anos da análise, até que em 2013, o quadro se inverte e o PIB supera, em valor absoluto, o peso morto ocasionado pela indústria automotiva. Ainda em relação ao comportamento do PIB dos estados supracitados e do DWL 
obtido para o segmento de carros 1000 cilindradas no Brasil, de 2005 a 2014, apresenta-se na Figura (2) uma comparação desses valores.

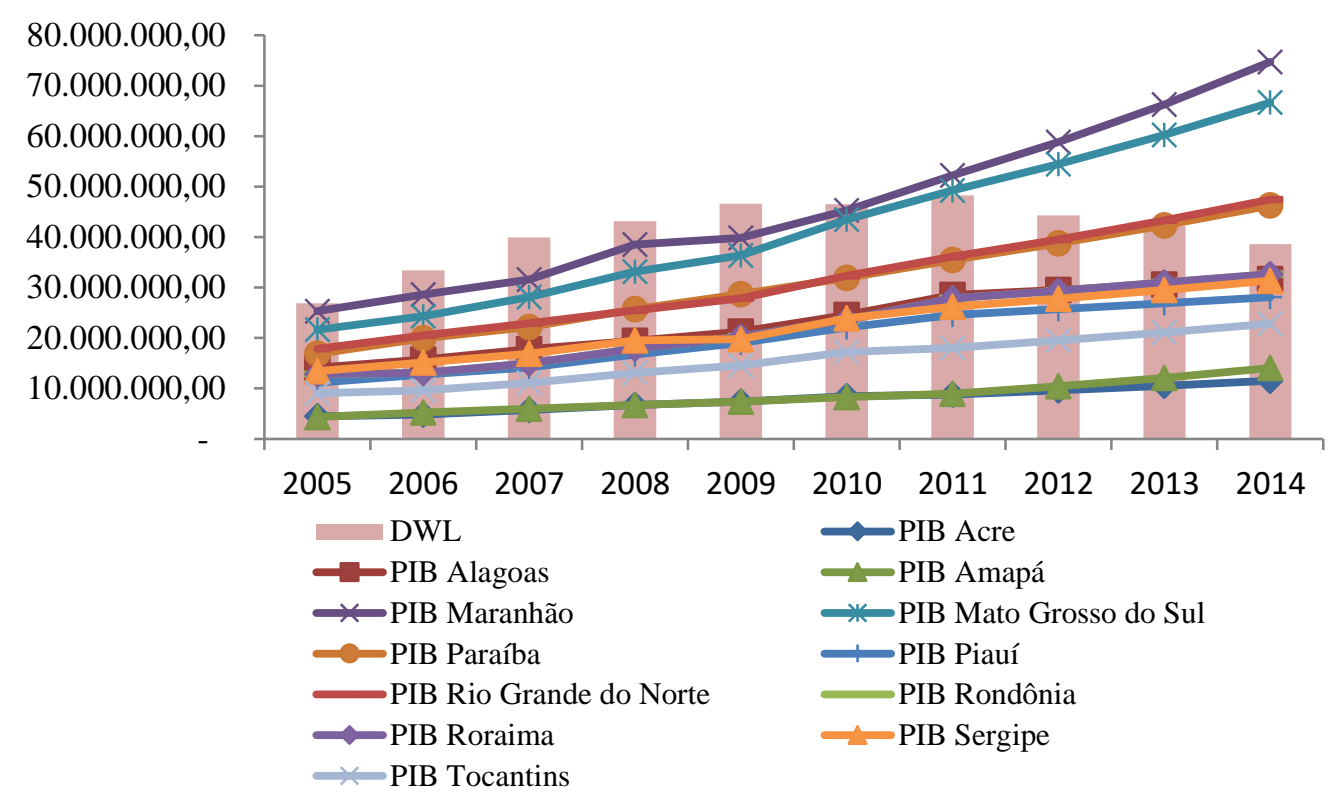

Figura 2- Comparação do PIB de alguns estados brasileiros e do peso morto segmento de carros 1000 cilindradas no Brasil, 2005 a 2014

Fonte: Elaboração própria a partir de resultados da pesquisa.

Ao observar a Figura (2), é possível constatar que há um crescimento contínuo dos PIB's estaduais, ao longo do período analisado. Já em relação ao DWL, este atingiu seu ápice em 2011, e a partir de 2012, começa a ter uma leve redução. Algo que pode ter ocasionado essa redução, é o término da isenção do Imposto sobre Produto Industrial (IPI), e em 2013, a alíquota para carros 1000 cilindradas começa a ser cobrada, o que afeta diretamente a indústria automobilística, visto que o custo para produzir um carro aumenta, e consequentemente, este custo é repassado ao consumidor. Isso acaba afetando os excedentes, tanto do consumidor quanto do produtor, afetando também o DWL por consequência.

\section{CONCLUSÃO}

O mercado de carros de 1000 cilindradas no Brasil é dominado por um pequeno número de grandes empresas que atuam nesse segmento. Com isso, aumentam-se as chances de o poder de mercado ser exercido e por conseguinte, gerar perdas de bem-estar e, por consequência, ineficiência econômica.

O objetivo desta pesquisa consistiu em analisar a estrutura de mercado e mensurar o bem-estar social no mercado de carros de 1000 cilindradas no Brasil no período de 2005 a 2014.

Foi observado que a produção de automóveis com motor de 1000 cilindradas no Brasil, para o período de 2005 a 2014, era de fato dominada pelas empresas Ford, Chevrolet, Fiat, Volkswagen e Renault que, em conjunto, detinham $98 \%$ do mercado em 2014, e em 2005, 96\%, e apesar de reduzir em 2 pontos percentuais, a participação encontrou-se ainda muito alta. Sendo assim, os índices de concentração CR5 e HHI indicaram que o mercado de automóveis de 1000 cilindradas de 2005 a 2014 era altamente concentrado. 
O cálculo da demanda também apresenta algumas informações relevantes, a saber: o salário mínimo apresentou significância estatística e o sinal esperado, e o coeficiente do preço foi inferior a um em valor absoluto, indicando que a demanda é inelástica.

Por fim, ao realizar cálculo e a análise dos resultados obtidos para o DWL, constatou-se que a geração de peso morto por parte das empresas que ofertam de carros 1000 cilindradas é bastante elevado, indicando que este setor não está operando com eficiência econômica.

Diante dos resultados encontrados e discutidos, não se rejeitou a hipótese nula de perda de bem-estar social, ocasionada pela concentração de mercado e demanda inelástica, apresentadas pelo segmento de carros 1000 cilindradas no Brasil, no período de 2005 a 2014.

\section{MARKET STRUCTURE AND MEASURE SOCIAL WELL-BEING IN THE 1000-CYLINDER CAR MARKET IN BRAZIL FROM 2005 TO 2014.}

Abstract: This research analyzed the market structure and measure social well-being in the 1000cylinder car market in Brazil from 2005 to 2014. The theoretical support was with the New Industrial and Empirical Organization and discussions on the measurement of dead weight, usually present in concentrated markets. In the empirical analysis, an econometric approach with panel data models was used to find the coefficients of the relationship between the demand for $1000 \mathrm{cc}$ cars in Brazil and their determinants and from the DWL was calculated. The results suggest that the market for 1000 cc cars in Brazil, from 2005 to 2014, is concentrated; demand is inelastic at a price; and, there was a significant value for the dead weight in this segment, suggesting the loss of well-being in the sector.

Keywords: 1000 cc cars in Brazil; Market concentration; Demand characteristics; DWL.

\section{REFERÊNCIAS BIBLIOGRÁFICAS}

ALMEIDA, F. A.; SILVA, A. S. B. Índices de Concentração: Evidências Empíricas à Indústria de Transformação Cearense. International Journal of Engineering Applied Sciences and Technology, v. 2, p. 9-13-13, 2017. Visitado (14/7/2018)

ANFAVEA- ASSOCIAÇÃO NACIONAL DE FABRICANTES DE VEÍCULOS AUTOMOTORES. Anuário da Indústria Automobilística Brasileira. São Paulo: Associação Nacional dos Fabricantes de Veículos Automotores. 2020. Disponível em:〈https://anfavea.com.br/anuario2020/anuario.pdf > Acesso em 08-01-2021.

- ASSOCIAÇÃO NACIONAL DE FABRICANTES DE VEÍCULOS AUTOMOTORES. Anuário da Indústria Automobilística Brasileira. São Paulo: Associação Nacional dos Fabricantes de Veículos Automotores. 2016. Disponível em: < http://www.virapagina.com.br/anfavea2016/files/assets/common/downloads/publication.pdf >. Acessado em 08-02-2021.

. ASSOCIAÇÃO NACIONAL DE FABRICANTES DE VEÍCULOS AUTOMOTORES. Anuário da Indústria Automobilística Brasileira - 2010. São Paulo: Associação Nacional dos Fabricantes de Veículos Automotores. 2010. Disponível em: $<$ http://www.anfavea.com.br/anuario.html $>$. Acessado em 10 set. 2015.

BAKER, J. B; BRESNAHAN, T. F. Empirical methods of identifying and measuring market power. 
Antitrust Law Journal. p. 67.1992.

BRESNAHAN, T. F. Empirical Studies of Industries with Market Power. In: Handbook of Industrial Organization, V. 2, Chapter 17. 1989.

CADE- CONSELHO ADMINISTRATIVO DE DEFESA ECONÔMICA. Guia de Análise de Atos de Concentração Horizontal. Brasília, 2016. Disponível em:< https://cdn.cade.gov.br/Portal/acesso-ainformacao/participacao-social/contribuicoes-da-sociedade/guia-de-ac-

horizontal.pdf?_ga=2.47039074.496034687.1612796937-805376222.16037411199> Acesso em 08-022021.

CONSELHO ADMINISTRATIVO DE DEFESA ECONÔMICA. Resolução n 20, de 9 de junho de 1999. Disponível em: $<$ http://en.cade.gov.br/cade/assuntos/normas-elegislacao/resolucao/resolucao-no-20-de-9-de-junho-de-1999.pdf/view> Acessado em 08-02-2021.

CHATURVEDI, A; BANDYOPADHYAY, S. Establishing a framework for analyzing market power in electronic commerce: An empirical study. HICSS-34. Hawaii, 2001. 34th Annual Hawaii International Conference on System Sciences, v. 7, p.7036.

CHURCH. J; WARE. R. Industrial Organization: An Strategic Approach. New York: McGraw-Hill. 2000.

CLARKE, R.; DAVIES, S.W. Market structure and price-cost margins. Economica, v. 49, p. 277-287. 1982.

COMUNELlO, A. L.; GODARTH, K. A. L. Medidas de concentração, variações de preço e desempenho: um estudo na indústria calçadista brasileira. UNIPAR Umuarama, v. 15, n1 p.25-40, jan./jun.2014.

DASKIN, A. J. Deadweight loss in oligopoly: A new approach. Southern Economic Journal, v. 58, n. 1, p. 171-185. 1991.

DE NEGRI, J, A. Elasticidade-renda e elasticidade preço da demanda de automóveis no Brasil.Rio de Janeiro: IPEA.Texto para discussão 558. 1998.

DIXIT, A.; STERN, N. Oligopoly and welfare: a unified presentation with applications to trade and development. European Economic Review, v. 19, p. 123-143. 1982.

FEDERAÇÃO DAS INDÚSTRIAS DO ESTADO DE SÃO PAULO- FIESP. Participação da indústria do PIB pode cair para 9,3\% em 2009, aponta estudo da FIESP. Set. 2013. Disponível em: $<$ http://www.fiesp.com.br/noticias/participacao-da-industria-no-pib-pode-cair-para-93-em-2029aponta-estudo-da-fiesp/> Acesso em março de 2018.

GUJARATI, D.N. Econometria Básica. Editora Campus. 5a edição. 2011.

HARBERGER, A. C. Monopoly and resource allocation. American Economic Review, v. 44, n. 2, p. 77-87, may. 1954.

MARTIN, S. Industrial Economics - Economic Analysis and Public Policy. 2. ed. New Jersey: Prentice Hall. 638 p. 1993.

PORTUGAL, M. S. As políticas brasileiras de comércio exterior. 1947-1988. Revista Ensaios (FEE). 15(1): 234-252. 1994. 
POSSAS, M. L. Os conceitos de mercado relevante e de poder de mercado no âmbito da defesa da concorrência. Rio de Janeiro, 1996, Instituto de Economia, UFRJ. <Disponível em:http://goo.gl/InefTH>. Acesso em 28 de Março de 2018.

RESENDE, M. Medidas de concentração industrial: uma resenha. Análise Econômica, Porto Alegre, ano 12, n 21 e 22, p.24-33, mar./set.1994.

SANT'ANNA, L. R. Análise da Concentração na Indústria Automobilística Brasileira nas Décadas de 1990 e 2000. Monografia (Graduação em Economia) - Departamento de Ciências Econômicas. Universidade Federal do Rio Grande do Sul. Porto Alegre. 2010.

SCHMIDT, C. A; LIMA, M. A. A Perda do Peso Morto e a Elasticidade-preço da Demanda do Setor Siderúrgico no Brasil. Estudos Econômicos, São Paulo, v. 36, n. 1, p. 127-147, Janeiro-Março. 2006.

TORRES, R. L.; CARIO, S. A. F. A governança da cadeia global de valor na indústria automobilística: um estudo de caso. Revista Econômica - Niterói.v.14.n.1.p.73-91. junho 2012.

WOOLDRIDGE, J. M. Introdução À Econometria - Uma Abordagem Moderna - Editora Cengage Learning, 6a Ed. 2017.

ZEIDAN, R. M. Robustez dos modelos da NEW empirical industrial organization (NEIO) com aplicação ao mercado brasileiro de cimento. Resumo do segundo ensaio da tese de doutorado Ensaios sobre Poder de Mercado apresentado ao IE/UFRJ em março de 2005.

APÊNDICE A - Teste de raiz unitária de Harris-Tzavalis (HT) para as séries do modelo de demanda por automóveis 1000 cilindradas no Brasil, 2005 a 2014.

\begin{tabular}{ccc}
\hline Variável & Teste HTdemean & p-valor \\
\hline LnSMR & 0,0001 & $0,00^{* * *}$ \\
LnPM & 0,0001 & $0,00^{* * *}$ \\
LnQ & 0,0001 & $0,00^{* * *}$ \\
LnG & 0,0001 & $0,00^{* * *}$ \\
\hline
\end{tabular}

Fonte: elaboração própria com base nos resultados da pesquisa.

Nota: $(* * *)$ refere-se a significativo a $1 \%$ de significância estatística.

APÊNDICE B - Resultados dos testes de Chow e Hausman

\section{Teste de CHOW}

$$
\begin{aligned}
& F(4,560)=48,79 \\
& \text { Prob > F =0,0000 } \\
& \mathrm{H}_{0}=\text { modelo MQO } \\
& \mathrm{H}_{\mathrm{a}}=\text { modelo } \mathrm{EF}
\end{aligned}
$$

\section{Teste Hausman}

$\chi^{2}=193,44$

Prob $>\chi^{2}=0,0000$

$\mathrm{H}_{0}=$ modelo EA

$\mathrm{H}_{\mathrm{a}}=$ modelo $\mathrm{EF}$

Fonte: Elaboração própria a partir dos resultados da pesquisa.

Nota: $\mathrm{H}_{0}$ refere-se a hipótese nula; Ha refere-se a hipótese alternativa; Prob denota a probabilidade de se rejeitar a $\mathrm{H}_{0}$; MQO refere-se ao modelo de mínimo quadrados ordinários; EF refere-se a efeitos fixos; EA refere-se a efeitos aleatórios. 